\title{
EduOpen: Italian Network for MOOCs, First Three Months Evaluation after Initiation
}

\author{
Marina Rui \\ Department of Chemistry and Industrial Chemistry, University of Genova, Italy
}

Copyright $(2016$ by authors, all rights reserved. Authors agree that this article remains permanently open access under the terms of the Creative Commons Attribution License 4.0 International License

\begin{abstract}
EduOpen is an Italian national network devoted to foster the MOOCs diffusion, not just another national provider, being mainly focused to intervene in some crucial fields such as: educational innovation, internationalization strategy, educational research on OER in order to build up some strategy of diffusion and also to make an effort of training those people involved into ICT supported education. It has been officially launched December $30^{\text {th }} 2014$ by seven universities, along with EDUNOVA (an Interuniversity Centre for supporting innovation technology in education, communication and research), by answering a project call of Miur (Italian Ministry of education). The founding universities are: the Polytechnic of Bari and the Universities of: Bari, Ferrara, Foggia, Modena and Reggio Emilia, Parma and Genova. The kick off took place April $20^{\text {th }} 2015$ and the official opening has been April $21^{\text {th }} 2016$ on the Miur premises; During this time, the network tuned various experiences of partners, defining and refining its own guidelines, according to both the literature and the Italian agency's recommendations (ANVUR). Nowadays, the number of universities increased up to sixteen and other ones are being negotiating their entrance
\end{abstract}

Keywords EduOpen, MOOC, Open Educational Resources, Network

\section{Introduction}

The distance education dates back many years, being much older than Internet, first leaning on postal services, and then on telecommunications, as the schools in the vast territories of Australian farms; In Europe, just as an example, it is worth mentioning the distance learning at the "Fern Universität" of Hagen (Germany), which made use of postal communication between students and teachers just up a few decades ago. The rise of the Internet has enabled a turning point in communication, as in many other fields; anyway, it seems that the term MOOC has being coined just in 2008 for an open online course: "Connectivism and Connective Knowledge" delivered by the University of Manitoba, Canada, see Downes [1]. Nowadays, a MOOC is characterized by a strong combination between topics and delivery platform and, in 2012 Daniel [2] named it "the educational buzzword of 2012". Gradually, since 2008, many academics have shown interest in MOOCs recognizing the potential to deliver education around the world on an unprecedented scale, as reported by Liyanagunawardena [3]. The starting point could be identified in USA, where, in 2001, MIT launched a pioneer open course (OpenCourseWare) for publishing permanently their own materials on the open Web, followed by Open University of UK with OpenLearn project and Carnegie Mellon University with its Open Learning Initiative. Anyway, all these initiatives were OER, but still not MOOCs, as reported by Fini [4], indeed all the materials were really free for use, but not organized within a course structure, and therefore not easily usable for users without enough skills. The MOOCs have become globally popular since 2011, when Stanford University has provided a free AI course that scored approximately 160,000 registrations of people from 190 countries, see Webley [5].

Nowadays "MOOCs or Massive Online Open Courses, based on Open Educational Resources (OER), might be one of the most versatile ways to offer access to quality education, especially for those residing in far or disadvantaged areas" to quote Daradoumis [6]. A typical MOOC has no preliminary requirements, no fees, no formal accreditation and each one is attended on voluntary basis, depending only by the peculiar interest of people, an ubiquitous learning in which anyone can deal with his pace; in a few years MOOCs are grown up and are exploiting different topics and methods: from traditional video plus self-assessments and fora up to collaborative spaces, supported by the power and versatility of the new tools, according to two of the most important theories: that of the independent study of Wedemeyer and Moore [7,8] and the collaborative learning of Kaye [9]. 


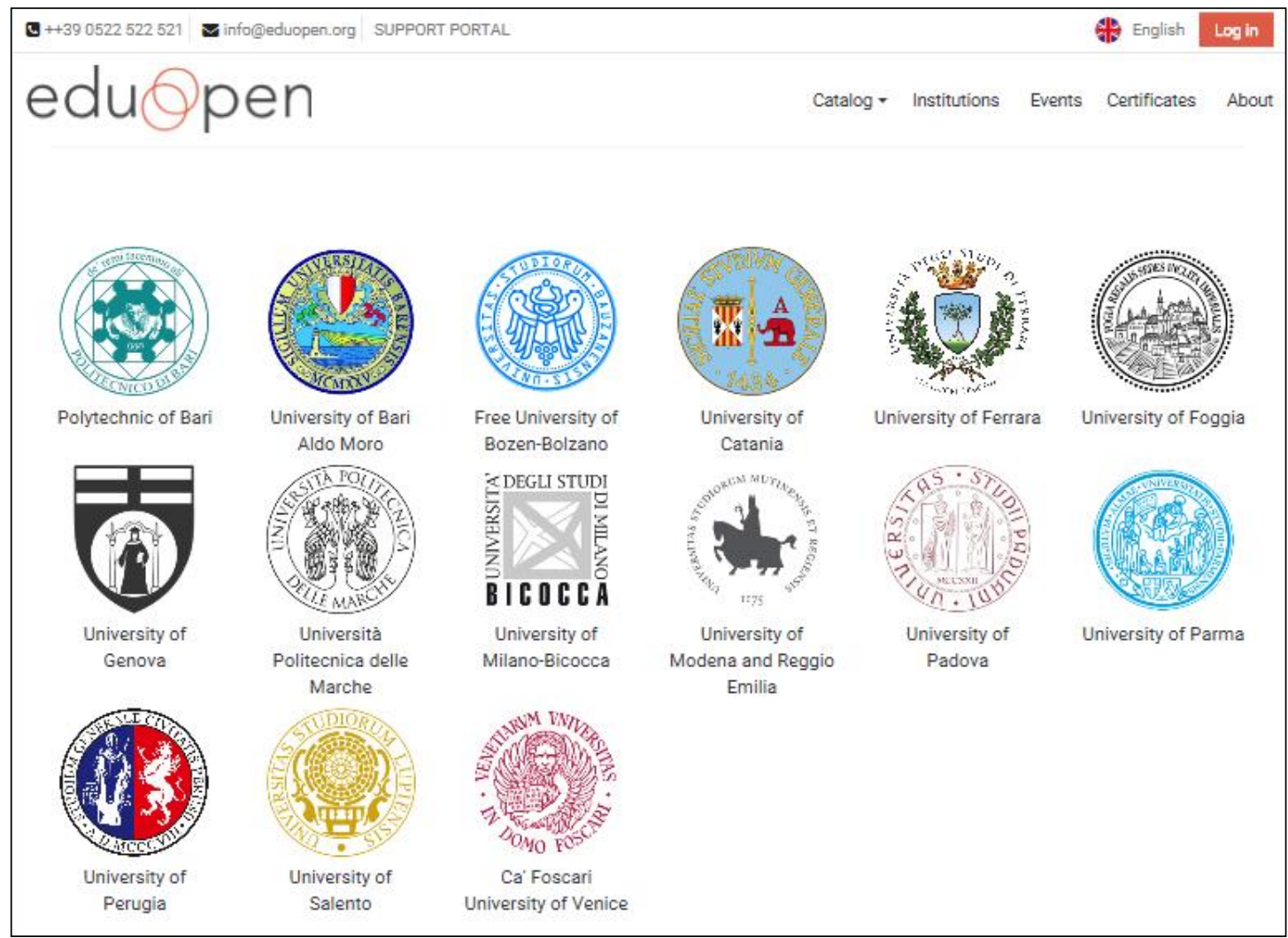

Figure 1. The page od EduOpen showing all the active university in july 2006

\section{Materials and Methods}

The EduOpen network will be discussed into the scenery of European providers together with its goals and structure. About the adopted methodology, it must be stressed that the partners spent quite one year discussing on what they considered the best way of interacting with totally unknown people with very spread out interests and attitudes. So, it was considered crucial that students could see the teacher's face in each lesson in order to foster the link with him/her, no matter of the chosen different didactic approach. Moreover, feedbacks are continuously collected by tutors answering on fora and, some courses, presented also a final satisfaction questionnaire that will be made available to all courses as soon as it will be refined. Another point to stress is the attention paid to the layout of the platform in order to make it as user friendly as possible, indeed nowadays the EduOpen environment already evolved before the first one presented at the end of April.

\subsection{The EduOpen Network and the Scenery of European Providers}

People could ask which reason for another provider, particularly a national one, for a relatedly small nation such as Italy, considering the wide spread out of giants, as Coursera, able to offer an enormous amount of subjects not just in English, but also in other languages as well as Italian. The answer lies on the initial statements: EduOpen is born to be more than a simple national provider, it is a project to perform various tasks that will be briefly illustrated below. It is bilingual (at least Italian and English) because it is not directed solely to the inner market; even if, up to now, the majority of courses shows video-lessons recorded in Italian, with the related materials in Italian or English; gradually all video will be captioned and new courses will be recorded in English, because the general policy is to have the majority of them truly bilingual. Just some basic courses will remain only in Italian because, in some fields, such as, for instance: the one about Internet, there are already a huge amount of the same subjects in English; instead, the ones of this kind on EduOpen are specially devoted to people mastering just their mother tongue, in order to overcome the double difficulty of language when facing a new topic of great interest for a highly varied audience. This information has clearly emerged both from the user profiles and by the responses to the satisfaction questionnaires that some courses (such as the one on Internet) proposed at the end of their activities. About the role of EduOpen as a provider, looking around Europe, the number of national ones is growing, some of them are quite big (for instance FUN for France, Iversity for Germany, Miriada, the Spanish one, from and to Latin America) that cover more and more significant percentages of users, as it can be seen browsing on Higher Education MOOCs [10]. It must point out that the emergence of platforms by different countries does not indicate localism, but instead a plurality of educational offer approaches, so true is it, that they often cross their national boundaries. Moreover, the share of 
English language courses has slightly reduced from $80 \%$ in 2014 to $75 \%$ in 2015, as says Dhawal [11], because also US-based providers like Coursera are now targeting international markets, and then increasing the offer in local languages. After English, the main languages for European MOOCs are Spanish and French, along with the presence of all the other national tongues, usually with caption in English for video lessons.

Coming back to EduOpen, let's give some information about its aims, the first one being the focus on "educational innovation"; there were already Italian Universities active in MOOCs for some years, the novelty comes out in comparing a good amount of those experiences and bringing together the best practices rose from the joint work of the partners that, starting from what is specified in the specialized literature, see, for instance, McAuley [12], developed its own trademark, which has then been taken into account also by the CRUI (The permanent Conference of Rectors of public Italian universities) when decided, the beginning of 2016, to build the rules for a national catalogue of certified MOOCs, that means online courses with strong and verified contents, effective way of approach and appropriate technological support in order to give a real opportunity to offer everybody access to high quality education, which responds, as well, to the so-called third mission i.e. the dissemination activities that is a duty of the universities towards their surrounding land.

\subsection{The Structure of EduOpen's MOOCs}

Each course on EduOpen maintains some peculiarity of its University but under a common general structure and layout; this has been a choice since the beginning of this plan, devoted to meet a wide variety of themes according to the peculiarities and the best skills of each partner university, not as a simple patchwork, but beneath a common unifying approach. In a nutshell, this could be the definition of EduOpen. Each course obeys to the same guidelines, to a common layout, must be tutored and must try to create a sort of temporary community among the users; for this reason, it was also sketched a satisfaction questionnaire, which refinement is still in progress, to obtain the opinions of users; some courses have already used its beta version, just to get a first raw feedback, of which some directions will reported further.

Beside the aim of "educational innovation" into the national scenery, it is crucial the will of implementing a strategy of internationalization in order to exchange the educational offer on EduOpen (the one in English) with other European universities in order to highlight the peculiar national competencies and also to have the critical mass needed to join the major European projects concerning OER, that means a target of investigation and not just of training. Connected to the previous point, there is a future plan of an extensive action-research of pedagogical and didactic matrix, the first in Italy to this extension, involving many cooperative universities, which will be useful for developing an "evidence-based" Italian strategy for the dissemination of OER. Furthermore, it will be taken particular care in investigating the formats and the interaction patterns, the evaluation techniques and the students "use practices" through learning analytics tools; in this field, indeed, the network presented also, a few months ago, a research project to Miur for future investigation. The results of all these studies will be devoted to enhance the training of faculty and staff to promote the effective use of best appropriate technology in different aspects of education. This will be crucial to minimize (as far as possible) the number of partially marooned projects, often due to the gap between the technological chosen media and the expected pedagogical purposes.

\subsubsection{The Guide Lines of the Network}

All partners sign the EduOpen guidelines both for creation and for delivering MOOCs, notably by ensuring the use of licenses "creative commons" and free delivery, through the EduOpen platform, of the whole material, including the issue of the badge which certifies the completion of the course, free and without legal value. The chosen licenses are: Creative Commons Attribution-NonCommercial 4.0 International and Creative Commons Attribution-NonCommercial-ShareAlike 4.0 International.

Anyway, each MOOC remains property of the providing University that can use it also in its usual institutional teaching plan.

In all courses, the teacher must be present in the video lessons with your own voice and image and he can use the most suitable tools he thinks his subject requires: slides, lim or whatever else; the shown materials, are also collected in a separate section for download. Each university is deliberately identified, but with a common graphic base to give unity and to ensure the user a comfortable path between the different courses. Learning materials are released weekly, using the Moodle's conditional activities with a check on the release date. After the release, they remain visible for the whole life of the MOOC.

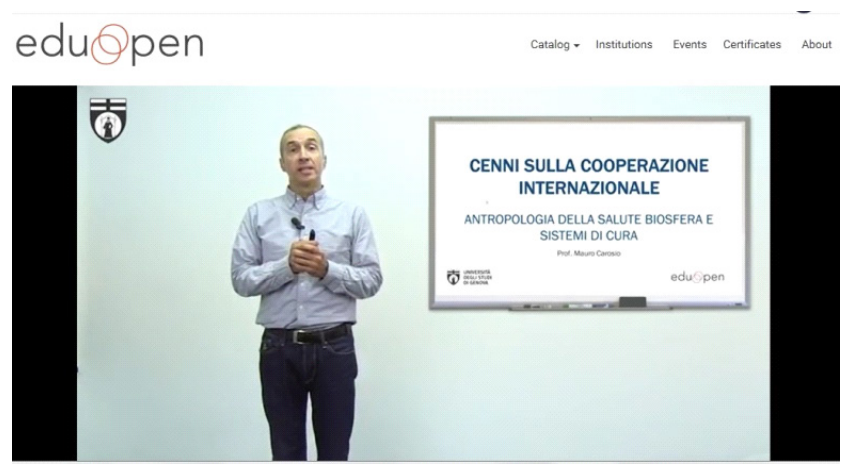

Figure 2. A screenshot of a video-lesson

\subsubsection{EduOpen Platform: a few Technical Information}

EduOpenLMS is the used Learning Management System 
(LMS) and it is based on Moodle; It is an Open LMS especially suitable for delivering MOOCs and Blended Courses based on a standard Moodle instance. Moodle is the most popular worldwide LMS, it is powerful and adopted by a large number of universities, schools and companies. However, the standard release of Moodle is not particularly suitable for delivering MOOCs or Blended courses, therefore, some significant amendments were required and they have been developed and maintained by a small, but active Indian start up: Dhruv Infoline Private Limited [13], in partnership with EDUNOVA [14] and the network of EduOpen partners, with the aim to add tools and features that make instances more efficient, complete and appealing. From a technical standpoint, it was decided to avoid a fork, so to don't change or modify the Moodle source code, but to develop add-ons to extend the functionalities related to requests for delivering MOOCs courses.

Here just the most significant of them:

- Eduopen theme was ad-hoc developed to show the courses and the catalog in an immediate and captivating way;

- A dashboard to see, at a glance, all the history of a user;

- A Learning Analytics block;

- Extra Settings for Courses: to add features and detailed descriptions of the courses;

- Full integration with Best, a platform for the release of Open Badge provided by CINECA $[15,16]$ : The Interuniversity Consortium, a major worldwide computer center in scientific research, public administration, health and of businesses;

- Full integration with IDEM-GARR [17] and eduGAIN. So that students, teachers and employees of the institutions, in Italy and in Europe, affiliated to EduGAIN [18] can use your own credentials to $\log$ in;

- Eduplayer, a plugin of Moodle to publish video-lessons.

\subsection{The Structure and the Life Cycle of MOOCs on EduOpen}

On EduOpen.org [19] there is the catalogue, updated at least year by year, of the whole active and future courses.
As already said, all the MOOCs of EduOpen are tutored; each course is usually covering 3-5 weeks of activities, but it lasts much longer (at least the double time) to allow anyone to attend with his/her own pace. The courses are structured in sections, each one is for a subject, and contains various activities such as: video-lessons and resources as documents, forums, collaboration tools, tasks, tests and so on.

Anyone who completes a course receives a Certificate of Participation, an Open Badge and, if provided by the university that produced the MOOC, also a Verified Certificate and Credits (ECTS).

Beside the single courses, people can also find out pathways, a structured set of courses related to a single subject with common and progressive educational goals. Each Pathway connects a sequence of courses and their whole completion can lead to acquire Credits or even serve as Postgraduate University's Courses or University's Masters.

Each pathway must contain:

- The sequence of courses;

- The presence of Milestones and Capstone;

- The procedures for comprehensive evaluation;

- Headers of each course belonging to it.

Within a Pathway, users can find courses labeled as "Milestone", which identify the achievement of intermediate educational objectives, and "Capstone", the conclusive and final part of a Pathway; anyway, each MOOC belonging to the pathway, is still a self-consistent course, with its own final Certificate of Participation, and can then be separately attended.

Obviously, the enrollment and attendance of MOOCs of EduOpen is always open and free for all, moreover, for some courses there is the additional possibility to achieve also validated certificates and this is declared into the catalogue with this "legenda":

- Level 0: no-label -Certificate of Participation and Badge (for all MOOCs);

- Level 1: Amber label -verified certificate;

- Level 2: Orange label - ECTS;

- Level 3: Red label-Advanced Course;

- Level 4: Dark red label- Master. 


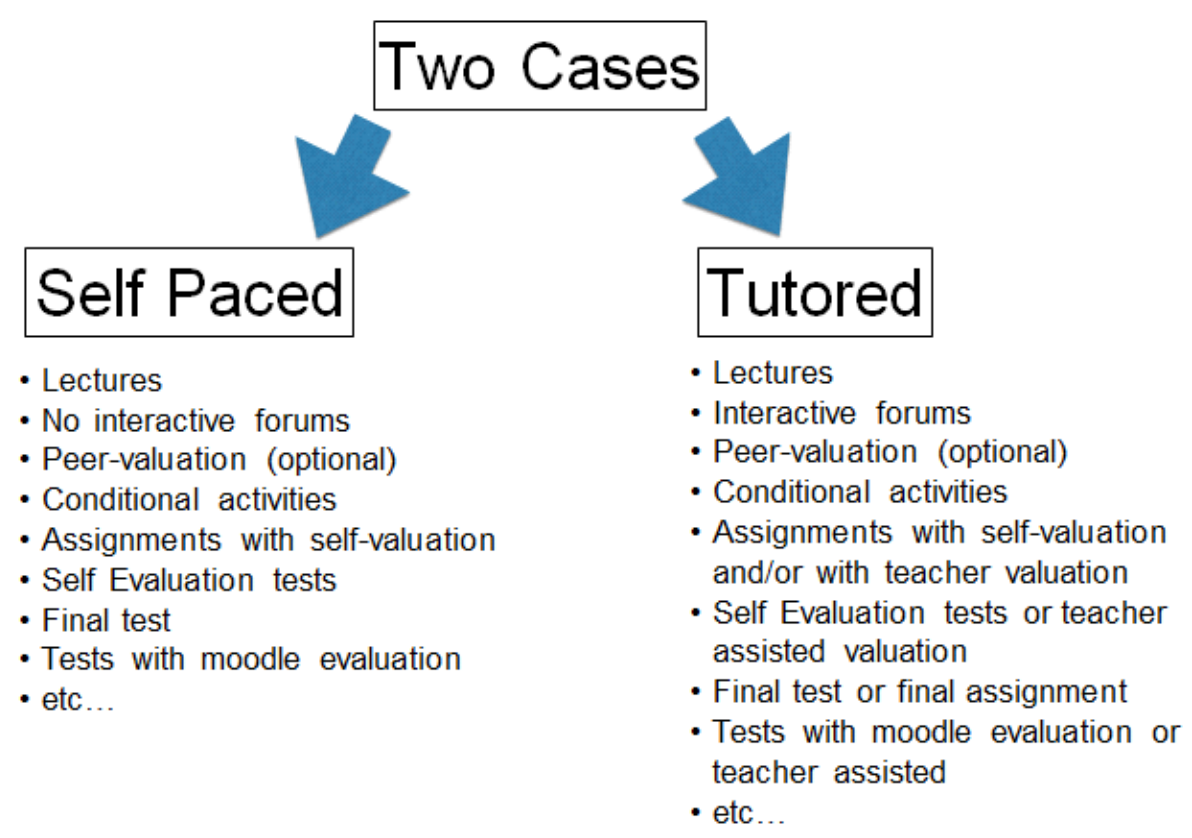

Figure 3. The pattern of a MOOC's life cycle on EduOpen

In figure 3 there is the typical pattern of the life cycle for a MOOC of EduOpen: each course starts being tutored and lasts in this modality more than a double of the weeks of predefined activities, after this time (that depend of the kind of course and how strong is the role of the interactive activities ), it remains open, even for new subscribers, or in a slow tutored way or in a self-paced way. The choice between the two modes depends on the significance of the interactive activities for the good outcome of the course, indeed, the slow tutored way implies just a more loosely tutoring, the self-paced mode is possible when all the activities proposed may be carried on without any kind of supervision. Even in the self-paced mode anyone concluding all the activities gets the Certificate of Participation.

Each course is temporarily closed just some weeks before the new edition in order to make updates and to collect the new subscribers which are interested to start from the beginning for playing a more interactive role and getting, if any, a higher certification. Depending on the kind of courses, the figure 3. the pattern of a MOOC's life cycle on EduOpen can be one to three editions per year. In this way each course remains open around ten months per year.

\subsection{The First Months of Experimentation of MOOC}

The network is fully operational by the beginning of May and, up to now, there have been forty courses delivered; just a few of them have already completed the planned weeks of activities and the other are still in their tutored mode, so it is possible to try just some very partial remarks; in less than three months, more than 17.500 people subscribed at least one MOOC, the average number of enrolled people is about 450 people per MOOC, with large differences depending of topics. The two most popular, for the moment, have been two courses: one about "Internet" and the other one about "how to learn English", both exceeding one thousand subscribers; some other courses, more targeted, as "Origins of Social Work" and "Animals ... who are they? Who we are?" ranging just below one hundred persons, anyway the subscriptions of these two courses are still open. It is surprising that some courses judged quite hard, such the ones about "Data mining" and "Python programming", each got four-five hundred subscribers.

Of course, these numbers are far away from the ones of Coursera, but it has to be considered that EduOpen is active for just three months and also that the majority of subscribers come from the national market; the majority, but not the totality, for instance, for some peculiar courses such as "Antropologia della salute - Biosfera e sistemi di cura" (that means: Anthropology of health - care systems and Biosphere), that is connected with the UNESCO Chair, active at University of Genova where there is also a specialized museum of ethno medicine, there are many attenders enrolled form Latin America. For the rest, depending of the subject, the stakeholders are much diversified, as happens with all MOOCs and also the times and the ways in which the average of members follows each course are the usually expected ones. The dissemination of news about the new courses have been very rapid and have followed both official channels but especially social networks.

By the data collected on one of the first courses, when it was already completed, but not yet closed, (the one about "Internet" with around than 1,200 subscribers), it is possible to see the current percentage of completion of the course with regard to the number of passed tests. The $16 \%$ of participants already passed all the tests and got the badge. More than half of participants (59\%) did not perform even one quiz and they are probably, in most cases, users simply curious to see what it is, typical of MOOCs. Analyzing the 
data of the platform it is possible to see the behavior of user regarding the different tasks and also during the time; of course each MOOC offers some differences related to its topics. From the data collected with the survey over the "Internet" course, the majority of participants consist mostly of adults over forty. Often workers or people looking for job, who have decided to join the MOOC for their personal culture or retraining. They consider that this course has been challenging and about the $70 \%$ of respondents claimed to have devoted more than 4 hours a week to online activity; anyway they look satisfied, would recommend the course to others and intend to follow other online courses in the future. It's interesting to note that many participants said that this has been their first experience of an online course.

\section{Conclusion and Perspectives}

Despite the knowledge that any statements quantitatively significant could not be done, nor could be provided any statistical model for the moment, it seems that the trend is encouraging. Indeed, new MOOCs are already in progress, and moreover, on the same Portal, some of us, belonging to seven universities, are preparing, under the leadership of the University of Modena e Reggio Emilia, two masters (first and advanced level) entitled "Open online learning" which the first one will start at the beginning of 2017 and is designed for giving expertizes of distance learning to teachers of different educational levels, educators and trainers. The overall of the two masters will cover a total of 120 ECTS over the two years that means: each master will cover 60 ECTS within the internship-stage in one of the partner universities. Anyway these two masters, that can be attended also separately, will have the same structure of all the EduOpen MOOCs and people could decide whether to sign up, from the beginning, to get the title, which is costly, or attend it as a free MOOC and only obtain the certificate of participation, or even decide to modify the free enrollment for achieving the full title along the way; In fact, the course will be structured to be usable in both ways, the only difference will be the internship at the end.

\section{REFERENCES}

[1] S. Downes, Places to go: Connectivism \& connective knowledge. Innovate, 5(1), 2008

[2] J. Daniel, Making sense of MOOCs: Musings in a maze of myth, paradox and possibility. Journal of Interactive Media in Education, 3, 2012

[3] T. R Liyanagunawardena, A. A. Adams, and S A Williams, MOOCs: A Systematic Study of the Published Literature 2008-2012, The international review of research in open and distance learning, Vol 14 | No 3 July/13, 2012;

[4] A. Fini, The technological dimension of a massive open online course: The Case of the CCK08 course tools. The International Review of Research in Open and Distance Learning, 10(5), 2009

[5] K. Webley, Time U.S., MOOC Brigade: Will Massive, Open Online Courses Revolutionize Higher Education?, nation.time.com.; Sept. 04, 2012

[6] T Daradoumis R. Bassi, F Xhafa., S.Caballe, "A Review on Massive ELearning (MOOC) Design, Delivery and Assessment," (3PGCIC), Eighth International Conference on P2P, Parallel, Grid, Cloud and Internet Computing, vol., no., pp.208,213, 28-30, Oct. 2013

[7] C.A Wedemeyer Independent study. In R. Deighton (ed.), Encyclopedia of Education IV, (p. 548-557). New York: McMillan, 1971.

[8] M.G. Moore, Independent study. In R. Boyd \& J. Apps (eds.), Redefining the Discipline of Adult Education. San Francisco: Jossey-Bass, pp. 16-31, 1980.

[9] A.R Kaye,. Computer-based collaborative learning,, TD Tecnologie Didattiche, Vol 2, No 1 pag. 9-21, 1994

[10] http://www.moocs.co/Higher_Education_MOOCs.html

[11] S. Dhawal, By The Numbers: MOOCS in 2015, https://www.class-central.com/report/moocs-2015-stats/

[12] A. McAuley, B. Stewart, G. Siemens and D, Cormier, The MOOC Model for Digital Practice, Knowledge Synthesis Grantson the Digital Econom y", 2010

[13] http://www.lmsofindia.com

[14] http://edunova.it/

[15] http://www.cineca.it/"cinecaHYPERLINK

[16] https://bestr.it/

[17] https://www.idem.garr.it/

[18] http://services.geant.net/edugain/Pages/Home.aspx

[19] http://www.eduopen.org/ 